Vol. 38(2), pp. 152-170, Dec. 2019

ISSN 1821-536X (print)

ISSN 2619-8789 (electronic)
Tanzania Journal of Engineering and Technology

Copyright (C) 2019 College of Engineering and

Technology, University of Dar es Salaam

Full Length Research Paper

\title{
Integrated Mobile and Web-based Application for Enhancing Delivery of HIV/AIDS Healthcare Information in Tanzania
}

\author{
Ibrahim A. Mwammenywa ${ }^{1^{*}}$, Michael H. Nkotagu ${ }^{2,3}$ and Shubi F. Kaijage \\ ${ }^{1}$ University of Dar es Salaam, Dar es Salaam, Tanzania. \\ ${ }^{2}$ Nelson Mandela - African Institution of Science and Technology, Arusha, Tanzania. \\ ${ }^{3}$ Ardhi University, Dar es Salaam, Tanzania. \\ *Corresponding Author: a.m.ibra90@gmail.com
}

\begin{abstract}
This study aims to develop an integrated e-health platform for enhancing delivery of HIV/AIDS healthcare information in Tanzania, which consists of a mobile application and a web-based system. The study is based on the system's functional and non-functional requirements for an e-health system for delivery of HIV/AIDS healthcare information. The Rapid Application Development (RAD) model was adopted during the system development. The system requirements were modelled into Data Flow Diagram (DFD) in order to obtain the clear flow of the HIV/AIDS healthcare information between the clients and HIV/AIDS healthcare practitioners. With the use of different software development tools and environment such as Android studio and Symfony framework; both android application and web-based system were developed. Finally, the developed system was tested for individual module functioning as well as the functioning of the fully integrated system. The user acceptance survey gave the mean score of above 4 on the scale of 5 for each tested aspect of the system. These scores show that the developed system was positively accepted by the users and commended the Ministry of Health and to deploy the system for enhanced delivery of HIV/AIDS healthcare information.
\end{abstract}

Keywords: Electronic Health (e-health), HIV/AIDS Healthcare Information, Mobile Application, Mobile Health (m-Health), Web-based System.

\section{INTRODUCTION}

The Government of Tanzanian has taken necessary socio-political and economic measures to fight against the HIV/AIDS pandemic. These measures include free provision of all HIV/AIDS healthcare services such as provision of free counselling, HIV testing services as well as Antiretroviral therapy (ART) in public hospitals (The Joint United Nations Programme on HIV/AIDS, 2016; Bor et al., 2013). However, most people are held back from freely accessing these
HIV/AIDS related services from HIV/AIDS Care and Treatment Centers (CTCs) due to fear of stigma (Saki et al., 2015; Feyissa et al., 2012; Mbonu et al., 2009).

In an on-going war against stigma towards people in need of accessing HIV/AIDS healthcare services; Lwoga et al. (2017) recommended that the HIV/AIDS public healthcare providers and the HIV/AIDS CTCs use an electronic platform to provide confidential access to relevant and formal HIV/AIDS healthcare information. The 
Information and Communication Technologies (ICT), being an electronic platform, brings about a great potential in enhancing the delivery of healthcare services including those for HIV/AIDS.

The increasing deployment of ICT solutions such as mobile communication technologies has opened the possibility of improving the delivery of so much important information to many people, at the same time without compromising their confidentiality. Mobile technology has been of different forms such as mobile money transactions, mobile health (mhealth), mobile security and control systems, and mobile banking and commerce. In particular, m-health applications have been growing fast recently, improving availability of healthcare services, health information, and influencing healthy user behaviour (van Genuchten et al., 2012). Thus, mobile health is expected to contribute in turning people's behaviour to reinforce disease prevention at a low cost of acquiring a quality healthcare service (van Genuchten et al., 2012; Qiang et al., 2012; ColeLewis and Kershaw, 2010; Mechael et al., 2010).

This research implements the recommendation made by Lwoga et al. (2017) of developing an e-health platform for enhancing the delivery of HIV/AIDS healthcare information services. With this e-health platform, an easy, timely and secured access to relevant HIV/AIDS healthcare information can be achieved. People will access the HIV/AIDS healthcare services such as clinical counselling, healthcare recommendation and tips with an enhanced confidentiality. The proper usage of the developed platform can significantly save the financial and time cost to clients. This is due to the fact that clients must not have to physically and frequently visit the HIV/AIDS CTCs for accessing the HIV/AIDS healthcare information such as
HIV/AIDS health tips and clinical consultation which can also be accessible through the developed electronic platform (Mwammenywa and Kaijage, 2018a). This is so essential in enabling people to access HIV/AIDS healthcare counselling and recommendations without being disclosed, identified and subjected to the stigma and hence, saving their lives. However, with such kind of e-health system, the practitioners will not always have the physical observations on the clients; forcing them to give recommendations and counselling based on the information received from the client.

\section{METHODS AND MATERIALS}

\section{System Development Approach}

In developing the e-health platform for HIV/AIDS healthcare information delivery, Software Development Life Cycle (SDLC) framework was employed. SDLC is a software development framework that outlines the tasks performed at each step in the software development process (Ragunath et al., 2010). There are different system development models with different characteristics as portrayed in Table 1.

The Rapid Application Development (RAD) model was adopted from the requirement acquisition to the system implementation and testing. It was adopted in order to hastily deliver the system within the given timeframe of 6 months, at a very low cost. Moreover, RAD provides the frequent developer-to-customer communication during the system development phases, hence it maintains the customer's satisfaction (Naz and Khan, 2015; Hirschberg, 2015; Dawson et al., 2010). Figure 1 illustrates the RAD model used in this research study.

\section{System Requirements}

Requirements for system development of an integrated mobile and web-based 
application for delivery of HIV/AIDS healthcare information are summarized into functional and non-functional requirements as was done in a previous study (Mwammenywa and Kaijage, 2018b). The function requirements given included the registration and management of users' accounts, provision of online HIV/AIDS clinical consultation, and online HIV/AIDS healthcare tips and recommendations. These functional requirements have been summarized in Figure 2 showing all the processes which will be accommodated by the system. Furthermore, the non-function requirements were also given including the need of system security, as well as offering services in both Swahili and English languages.

Table 1: Comparison between Different System Development Models

\begin{tabular}{|l|c|c|c|}
\hline \multirow{2}{*}{ Model } & \multicolumn{3}{|c|}{ Features } \\
\cline { 2 - 4 } \multicolumn{1}{|c|}{ Financial Cost } & Time $^{\mathbf{1}}$ & Functionality $^{\mathbf{2}}$ \\
\hline Waterfall & High & Long & Static System \\
\hline Incremental & High & Short & Static System \\
\hline Spiral & High & Long & Dynamic System \\
\hline RAD & Low & Short & Dynamic and Interactive System \\
\hline Agile & Low & Short & Dynamic System \\
\hline
\end{tabular}

Sources: Ismail (2018); Hanafiah and Kasirun (2007).

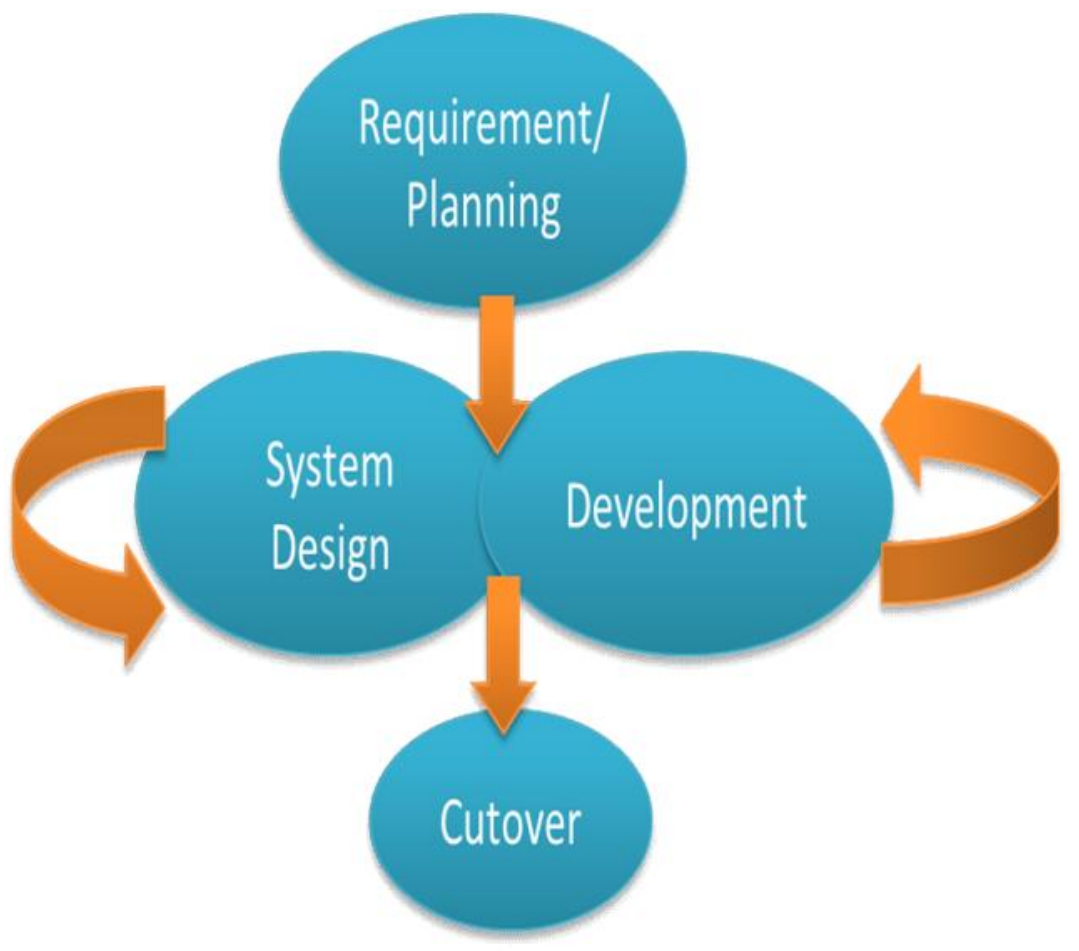

Figure 1: The System's Rapid Application Development (RAD) Model (Daassnet, 2018).

\footnotetext{
${ }^{1}$ Time - the total duration of time taken from the project initiation to its completion (all the stepes involved in the system development, from requirements gathering all-the-way to the system implementation and testing).

${ }^{2}$ Functionality - The interactivity of the system's functionalities such as in static systems where they do not allow the interactivity with the users; unlike the dynamic system in which their functionalities depend on the users' inputs.
} 


\section{System Designing}

The system design involved mapping of the system requirements into Data Flow Diagram (DFD). The following DFD diagram in Figure 3 shows how the information will be flowing from one actor/user to another.

All users must be registered in the system and use their correct credentials to access their profiles, which are classified based on their roles such as a client, an HIV/AIDS practitioner and a system administrator. The registered client will use mobile application to make an online clinical appointment and/or participate in an online clinic session with a HIV/AIDS health practitioner. Moreover, a client can access the HIV/AIDS healthcare tips and recommendation. A HIV/AIDS health practitioner is not only offering the online clinical consultation but also, he/she can post some HIV/AIDS health tips, recommendations and reminders. Figure 3 also shows the roles of the system administrator in providing the technical support to all users as well as managing the documents gallery.

\section{System Implementation Tools}

During the implementation of this platform, different software development tools were employed. These tools vary from the computer programming languages, database, to integrated development environment. The following is the description of system implementation tools used in this research study:

- PostgreSQL Database: is an opensource object-oriented relational database management system (ORDBMS) which supports most of the SQL standard with additional features. It supports features such as complex queries, foreign keys, triggers, updatable views, transactional integrity, multi-version concurrency and control. Furthermore, PostgreSQL allows developers to add some desired features such as adding new data-types, and functions, operators and procedural languages (Argyridis and Argialas, 2015). The PostgreSQL was employed in this study due to its ability to manage its internal security based on the user-roles, in additional to its support of external authentication mechanism such as password (supported by the HTTP authentication in Symfony framework).

- Android Studio: the client application is developed based on the android operating system. Android was selected due to its high user penetration with about $80 \%$ market share on the mobile operating system business (Statista, 2019). Android is an opensource mobile operating system for smart mobile gadgets such as smart mobile phones and tablets (Reto, 2009). Android Studio was employed in the implementation of the mobile application part of this study as shown in Figure 4. It was used due to its builtin functionalities and libraries such as the mobile application web view, maps and locations which are essential requirements for this developed system.

In this study, XML was mainly employed for developing the user interfaces in android mobile application. This was due to it being an open-source software (free), easier in offloading and reloading of data to and from database while maintaining the desired information and user interface appearance. With the desired user interface, the user experience on the mobile application is improved. Furthermore, Java was employed for its core libraries used in implementing the functionalities and some advanced User Interface (UI) features in implementing the android mobile application on the android studio. It 
simplified the development of some complex features of the developed mobile application.

- Symfony Framework: is a free PHP web-application development framework with a set of PHP components and libraries (Porebski et al., 2011; Radescu et al., 2011). Symfony framework was used in order to speed up the implementation of the web-application. It also helped in maintenance of the code by replacing the repeated coding tasks. Moreover, this framework provides the strong built-in security functions which not only provide the HTTP basic authentication, interactive form login and/or X.509 certificate login, but also allow the implementation of other authentication features.

- JSON: JavaScript Object Notation (JSON) is an open-standard and a programing language independent file format that employs human-readable text to convey data-objects containing attribute-value pairs and/or array data types (Bray, 2017; Crockford, 2006). It supports basic data types such as number (integers, floats, double), string, Boolean, array and null. JSON was used in this system development for transmitting the array of data from the mobile application to the web application to the database. This simplifies the connection between the database and the mobile application.

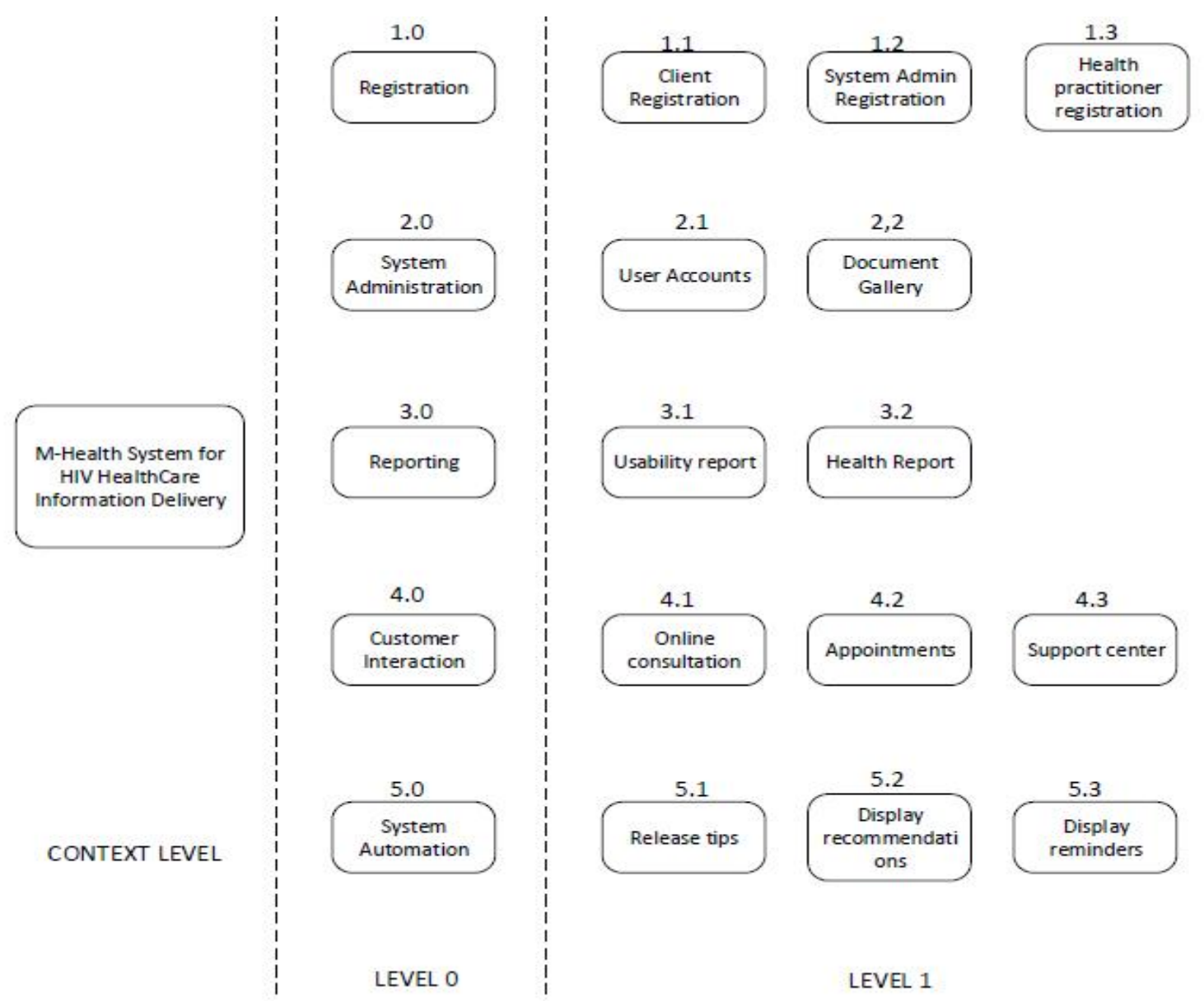

Figure 2: The Process Decomposition Diagram for a Secure e-Health Platform for HIV/AIDS Healthcare Information Delivery 


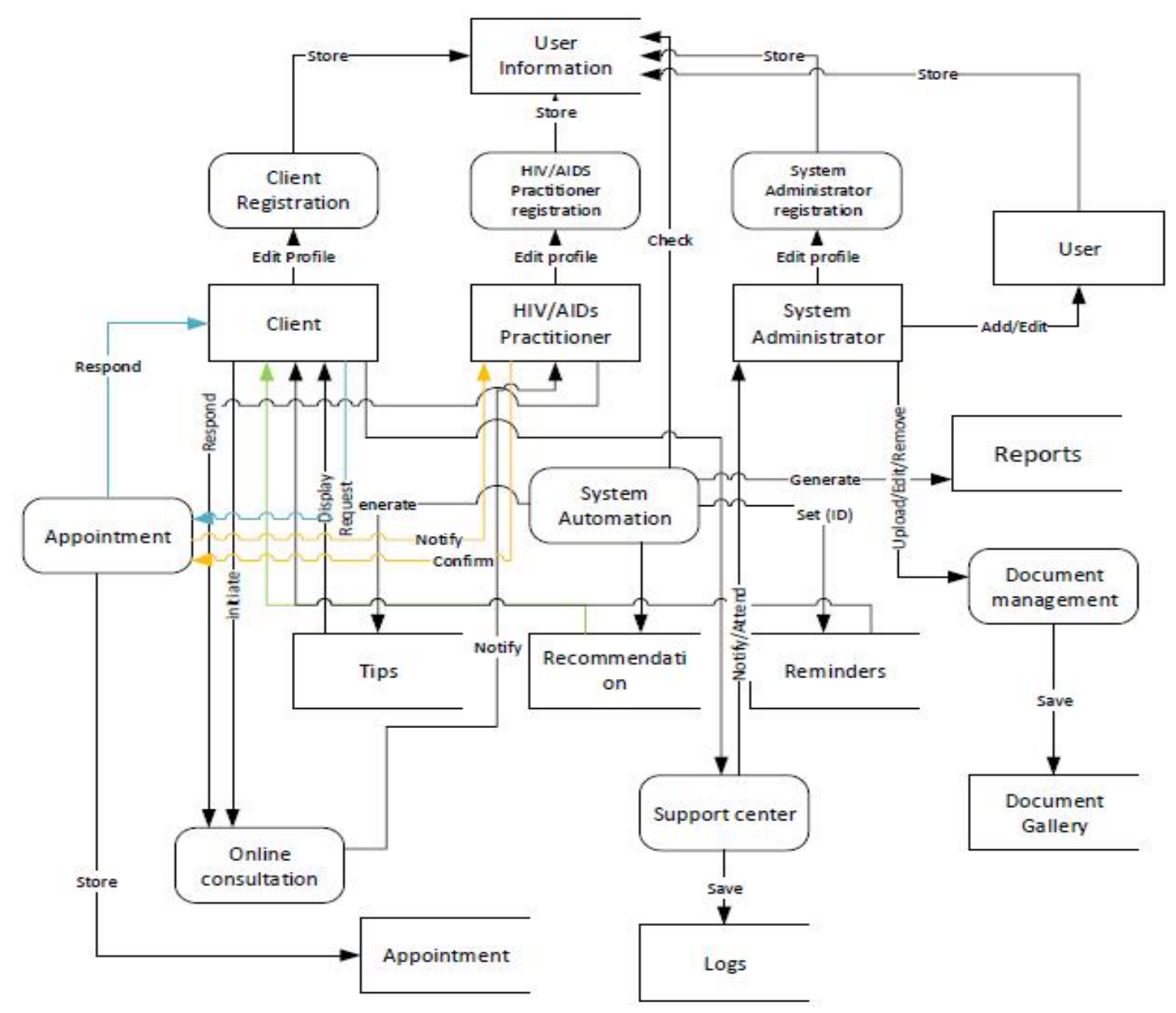

Figure 3: Data Flow Diagram for a Secure e-Health Platform for HIV/AIDS Healthcare Information Delivery

- WebSocket: is the communication protocol responsible for the full-duplex communication channels over a TCP connection. It enables the real-time interaction between a web-client and a web-server, doing so; it enables the real-time data transfer at low overheads. This is possible as WebSocket enables the streams of messages on top of TCP (Pimentel and Nickerson, 2012; Fette and Melnikov, 2011). It is currently supported by majority of the browsers such as Google Chrome, Microsoft Internet Explorer and Opera for both computers and smart mobile phones. The WebSocket was employed during the development of real-time communication module. This module is to enable the real-time chatting communication between the service client and the HIV/AIDS healthcare practitioners.

- Genymotion: During implementation of the mobile application, the android simulated phone (Genymotion) was used. However, during the testing of the mobile application, different set of physical gadgets (both mobile phones and tablets) running Android OS were used. The mobile application development put a limit at the android version 5 (Lollipop) to accommodate those with lower version even though the least currently supported version is android version 7 (Nougat). The hardware specifications of mobile gadgets used were CPU: Hisilicon 
Kirin 710F (Huawei), Exynos 9810 (Samsung); Core: Dual-core and Quadcore; and RAM: $1 \mathrm{~GB}-4 \mathrm{~GB}$.

\section{SYSTEM IMPLEMENTATION}

\section{Database Implementation}

The mobile and web applications in this system are supported by the PostgreSQL database management system. A number of JSON and PHP scripts have been used in connecting the database with the client's application to allow smooth and consistency data manipulation (including data insertion, updating, retrieval and deletion). The database schema contains 14 tables and their relation is displayed in the Figure 5.

\section{Mobile Application Implementation}

The mobile application was developed based on android platform. It contains the simple and easy to use user-interfaces (UIs) to provide the interaction between user and application. This application is only for HIV/AIDS healthcare services clients. It is based on both English and Swahili languages; whereby a user can select the language of his/her preference before logging into the system as shown in Figure 6.

Before logging into the system, user must have an activated and registered account. During registration, the client will have to submit personal particulars which are useful for HIV/AIDS healthcare practitioners in delivering healthcare services. Some of these particulars are gender, age, weight and height.
After successful registration, the client will be required to use his/her unique display name (not a real name for the sake of maintaining anonymity) and password to $\log$ into the system. After successfully logging into the system, the client will be presented with the menu containing all the HIV/AIDS healthcare information services provided by this platform. Figure 7 shows the menu UI.

To maintain the client's confidentiality and anonymity, the mobile application provides the client with the logout option. This option will terminate the communication session between his/her profile and the system. Hence, none can be able to use his/her account.

\section{Web Application Implementation}

The web system was developed as a crossplatform of all web browsers (Figure 8). It provides the interfaces for HIV/AIDS healthcare practitioners as well as the system administrators working in the CTCs. These web application interfaces help them in offering services such as uploading healthcare tips and answering the frequently asked questions.

Both the HIV/AIDS healthcare practitioners and system administrators must be registered into the system and have to log into the system with the unique username and password. Figure 9 shows the login page for HIV/AIDS practitioner and system administrator respectively. For each kind of user, his/her account is associated with some specific roles. 


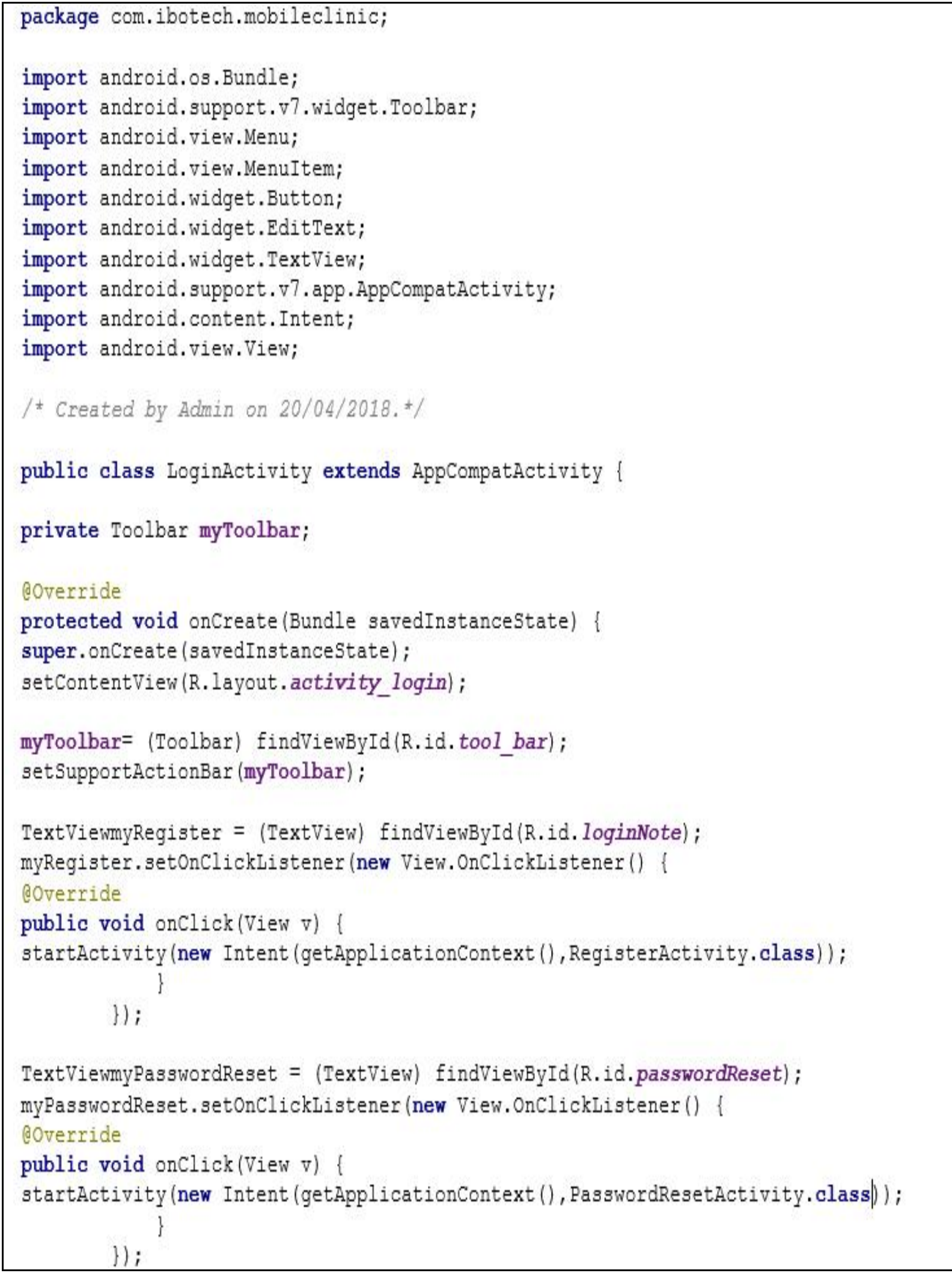

Figure 4: The Code Snippet for Android Application Implementation on the Android Studio 
Integrated Mobile and Web-based Application for Enhancing Delivery of HIV/AIDS Healthcare Information in Tanzania

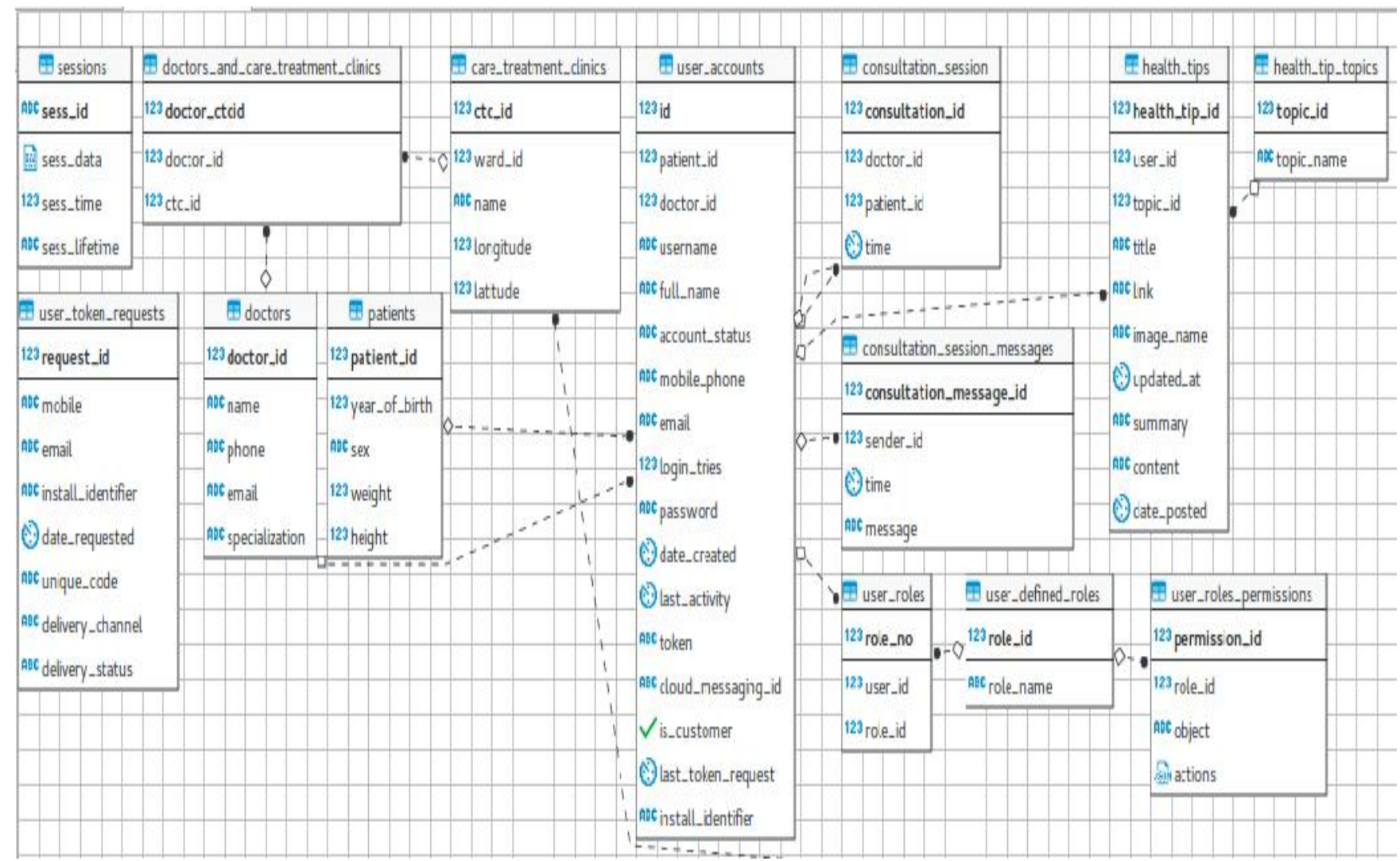

Figure 5: Entity Relational Schema
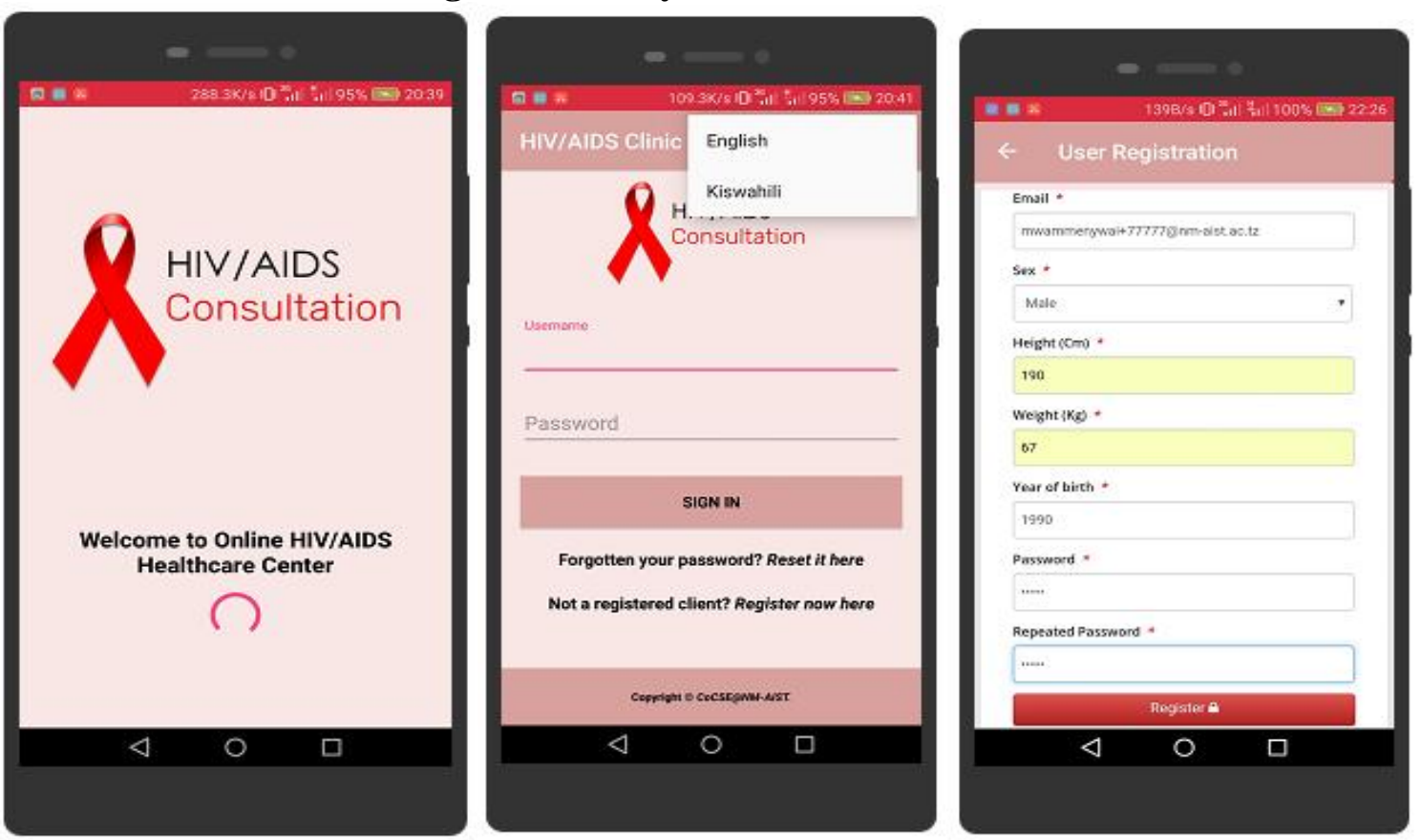

Figure 6: Mobile Application's Login and User Registration UIs 

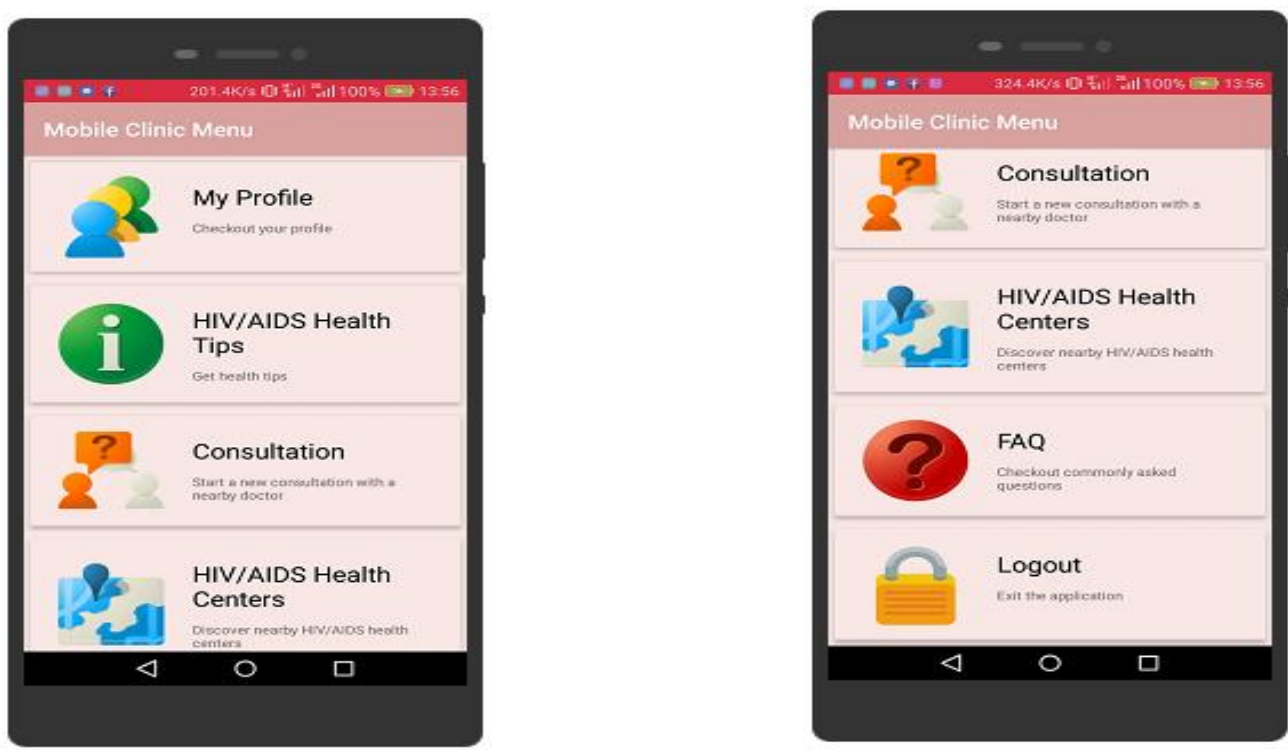

Figure 7: Mobile Application's Main Menu UI

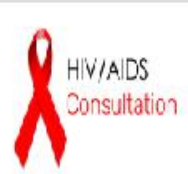

\section{HONE MYCONSULTATION ABOUT CONTACT LS}

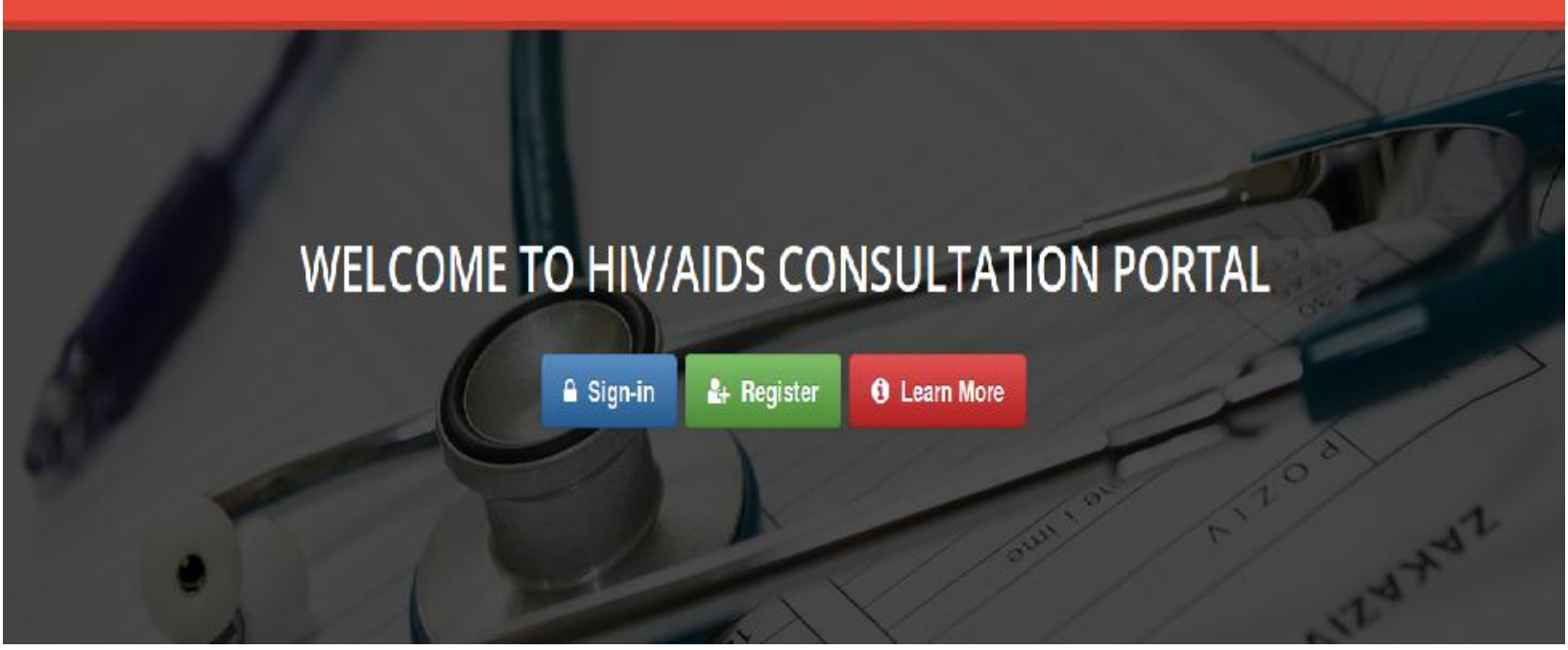

Figure 8: Web Application's Welcome Page 


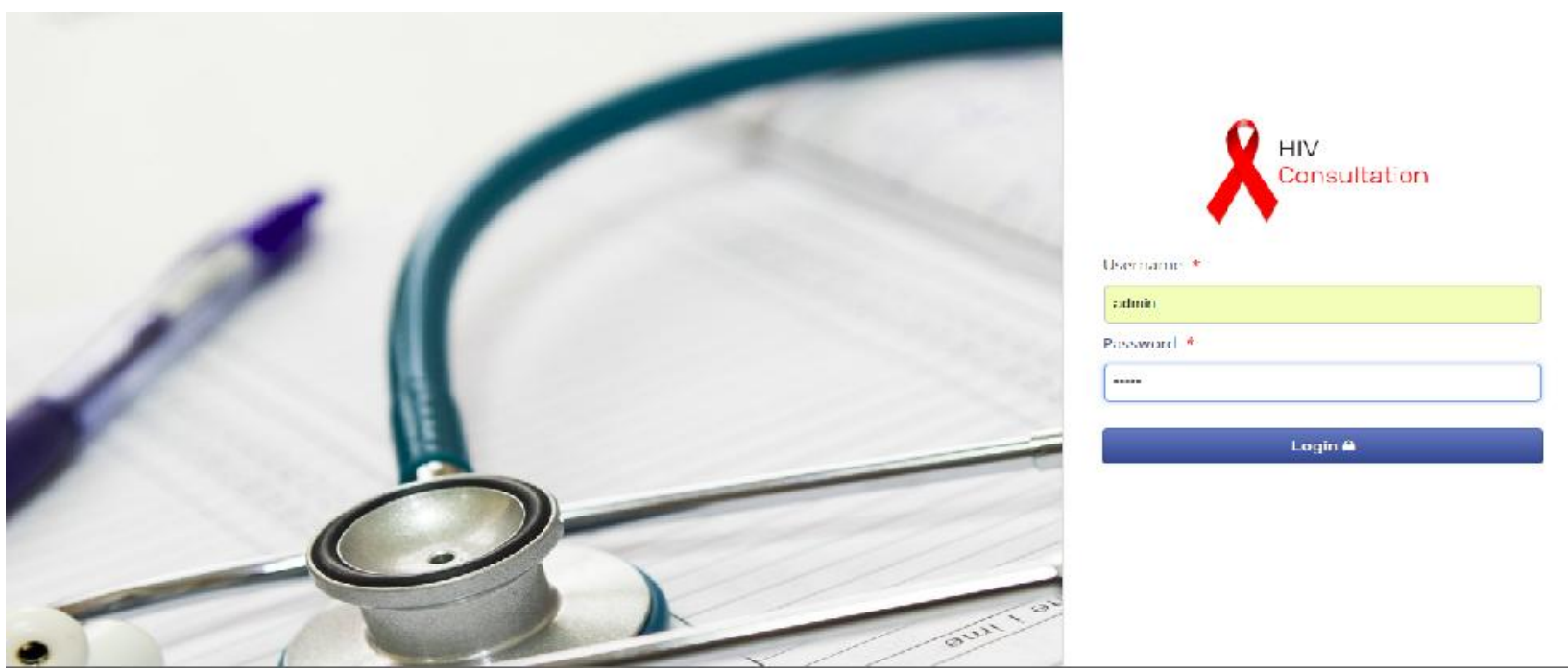

Figure 9: Web Application's Login Page

Once the HIV/AIDS healthcare practitioner has logged into the system, he will be provided with the list of clients who have logged into the system seeking for the consultation session. The practitioner will select one client and start the live chat consultation with him/her, as shown in Figure 10.

Furthermore, the system administration web page provides the system administrators with different roles such as managing users, health tips, providing support and others. Figure 11 shows an example of the system administrator's web page when managing users.

\section{SYSTEM TESTING AND VALIDATION}

\section{System Testing}

The system's modules were tested to determine if they are working as per defined system's requirements. Table 2 shows the test results for different tested modules. Some of the tested modules have been shown below:
- HIV/AIDS Healthcare Tips: The client can view different HIV/AIDS healthcare tips as they are posted by the qualified and registered HIV/AIDS healthcare practitioners. These tips are arranged in the order of time they are posted, with the newest at the top as shown by Figure 12(a). Once the tip is clicked, it provides the client with more details on itself as shown in Figure 12(b).

- Consultation: This is the chat space for the mobile application's client to realtime interact to the HIV/AIDS healthcare practitioner. Figure 13 shows how the client can interact with the HIV/AIDS healthcare practitioner for counselling and healthcare recommendations.

- HIV/AIDS Health Centers: In order for the system to help the client who needs a physical healthcare from the physician, the mobile application provides the client with the map showing the route to the nearest HIV/AIDS CTC. Figure 14(a) shows the nearest CTC. With the help of the google map services, the shortest route to the nearest CTC can be achieved either by car, or by foot as depicted in Figure 14(b). 


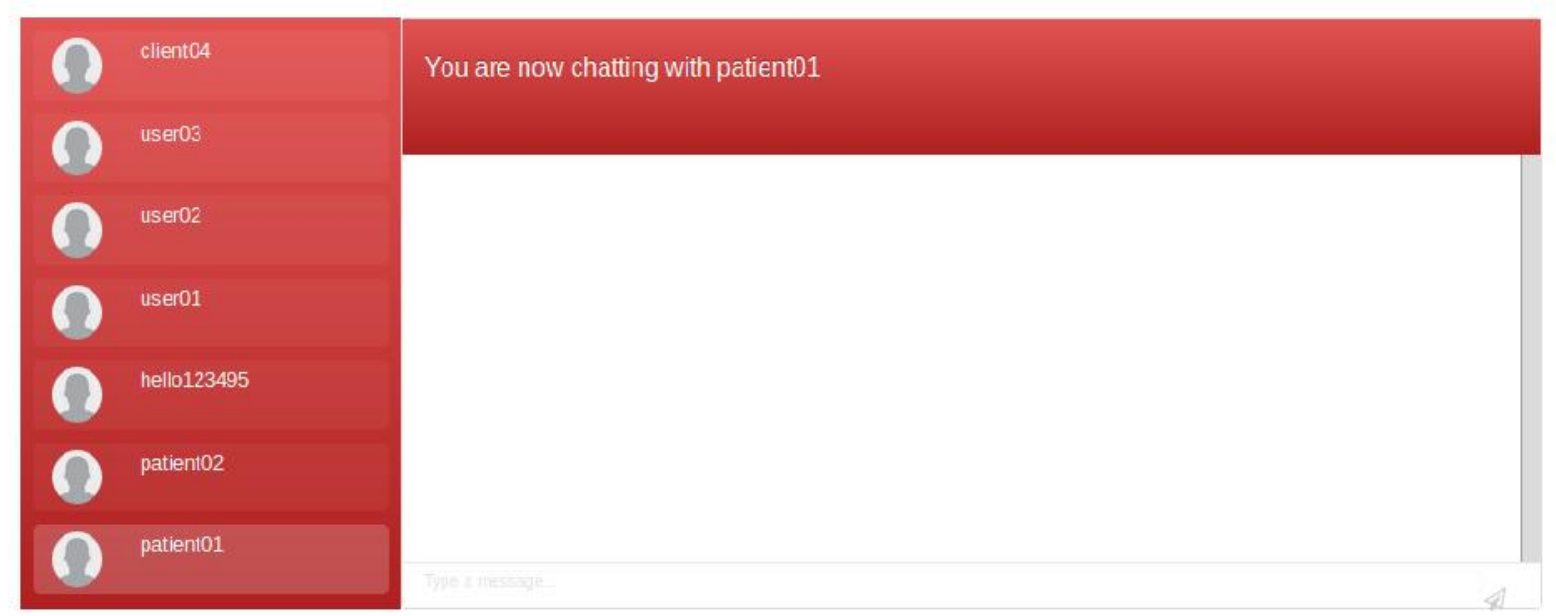

Figure 10: Web Application's Consultation Live Chat Web Page for HIV/AIDS Healthcare Practitioner

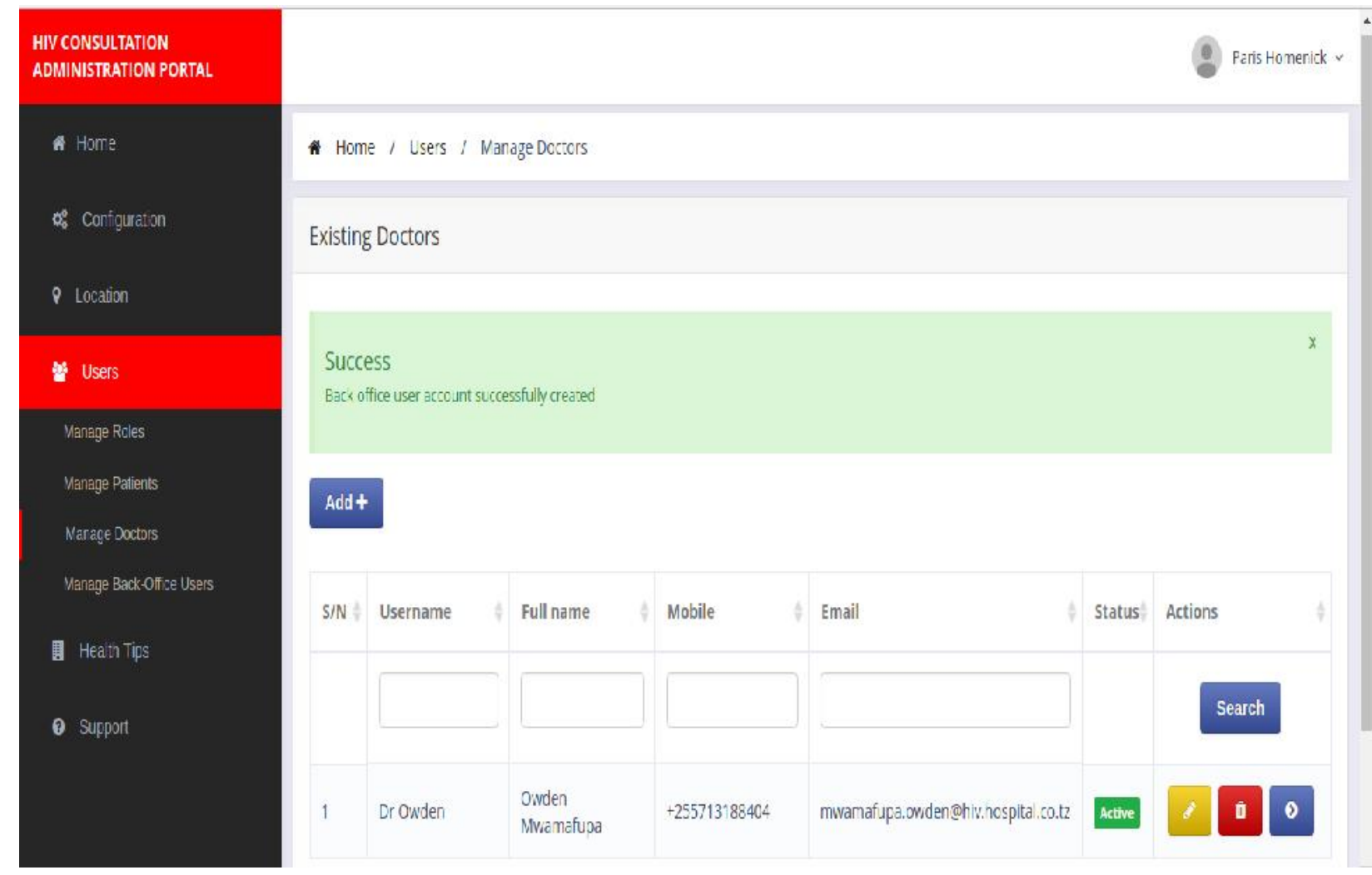

Figure 11: A Web Application's Page for the System Administrator Managing Users' Account 
Table 2: System's Modules Testing Results

\begin{tabular}{|l|c|}
\hline \multicolumn{1}{|c|}{ System Requirement } & Test Result \\
\hline $\begin{array}{l}\text { The web system should be compatible with all browsers and mobile } \\
\text { application should work on the android OS }\end{array}$ & PASS \\
\hline $\begin{array}{l}\text { The mobile application should enable user to switch languages from } \\
\text { English to Swahili }\end{array}$ & PASS \\
\hline The system must allow registered user to login and logout & PASS \\
\hline $\begin{array}{l}\text { The system must allow unregistered client to register himself/herself with a } \\
\text { unique username }\end{array}$ & PASS \\
\hline $\begin{array}{l}\text { The system must allow the system administrator to create, suspend or } \\
\text { remove a user account for the HIV/AIDS healthcare practitioners }\end{array}$ & PASS \\
\hline $\begin{array}{l}\text { The system should allow the system administrator to upload and/or remove } \\
\text { HIV/AIDS health tips and other healthcare information }\end{array}$ & PASS \\
\hline $\begin{array}{l}\text { The system should provide the live chat capability between the client and } \\
\text { HIV/AIDS healthcare practitioner; the healthcare practitioners to use this } \\
\text { module for provision of healthcare recommendations }\end{array}$ & PASS \\
\hline $\begin{array}{l}\text { The system should allow all successfully logged users to view the } \\
\text { HIV/AIDS health tips and other healthcare information }\end{array}$ & PASS \\
\hline $\begin{array}{l}\text { The system should produce different reports as requested by the system } \\
\text { administrator }\end{array}$ & PASS \\
\hline
\end{tabular}

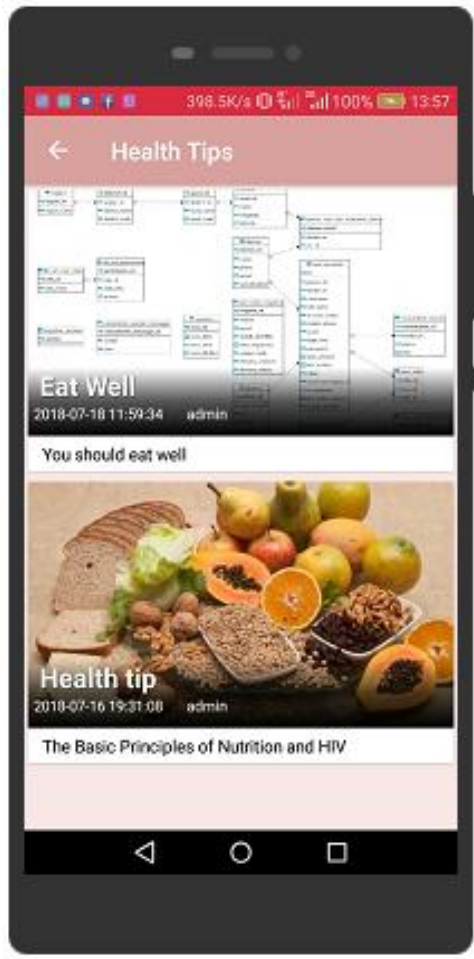

(a)

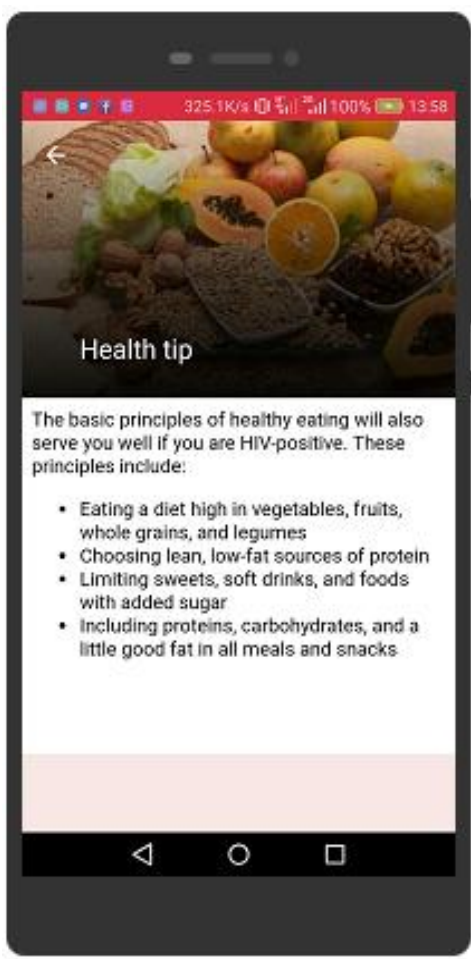

(b)

Figure 12: Mobile Application's HIV/AIDS Healthcare Tips UI 


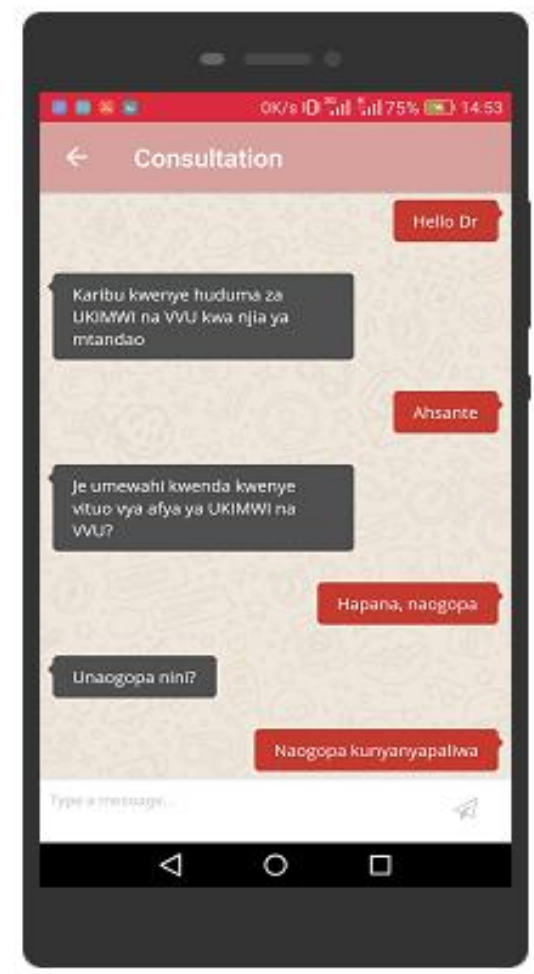

\section{Figure 13: Mobile Application's HIV/AIDS Consultation Live Chat UI}

- Frequently Asked Questions (FAQ): The mobile application also provides the answers for the frequently asked questions. These questions are answered by the system administrators with consultation to the HIV/AIDS healthcare practitioners. Figure 15(a) shows the questions, and when the question is clicked, it displays its answer as shown in Figure 15(b).

- Client Profile: The client is able to view his/her profile and even update his/her personal information as shown in Figure 16. At this UI, the client can change his/her password to enforce his/her account's security. During the password reset, the system will send the verification code to the client's email for confirmation before allowing the password reset. Figure 16 shows how the particulars are displayed and how to update them.

\section{Users' Acceptance Validation}

With the system fully developed, it was taken into the practical environment for user's acceptance validation. Fifteen (15) people participated in this system validation survey, among them, 10 clients who installed the mobile application in their mobile smart phones, 3 HIV/AIDS healthcare practitioners and 2 system administrators. All participants were given 3 days to use the system and after then, they filled in the survey questionnaires. The survey results were computed on the mean score based on a five-point Likert scale $(5=$ Strongly Agree; $4=$ Agree; $3=$ Not Sure; 2 = Disagree and 1 Strongly Disagree) as displayed in the Table 3.

From the study, the mean score for each validated aspect was above 4 in the scale of 5, showing that the majority of the sampled respondents strongly agreed with the quality and ability of the developed ehealth system. The sampled users of the system even recommended that the Ministry of Health (and other related healthcare stakeholder) should employ this developed system for delivery of HIV/AIDS healthcare information. 
Integrated Mobile and Web-based Application for Enhancing Delivery of HIV/AIDS Healthcare Information in Tanzania

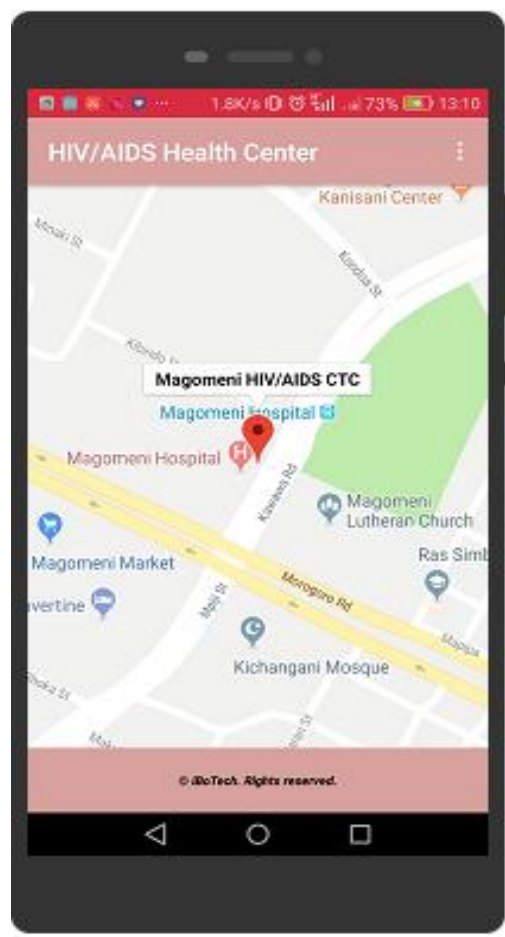

(a)

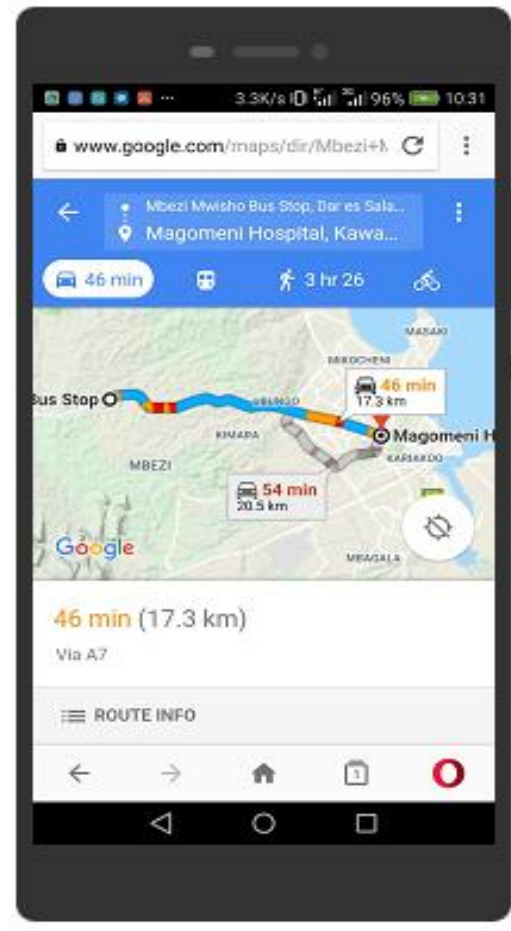

(b)

Figure 14: Mobile Application's nearest HIV/AIDS CTC Locator UI

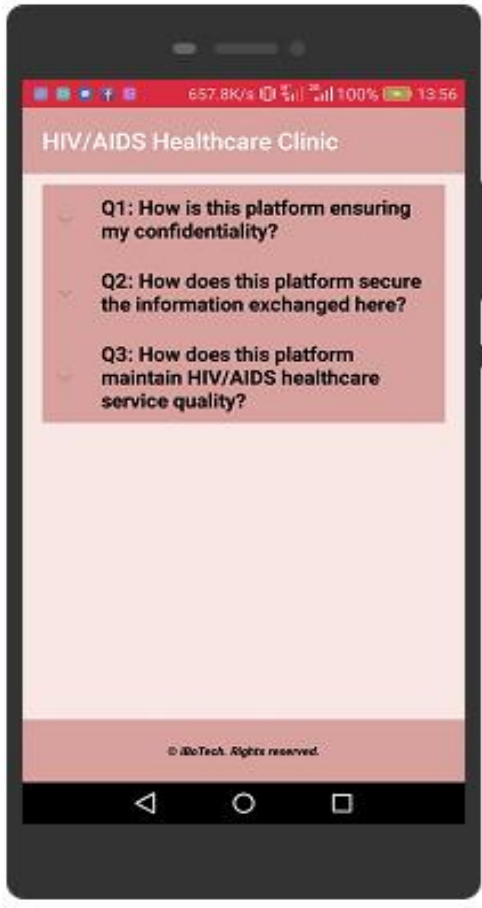

(a)

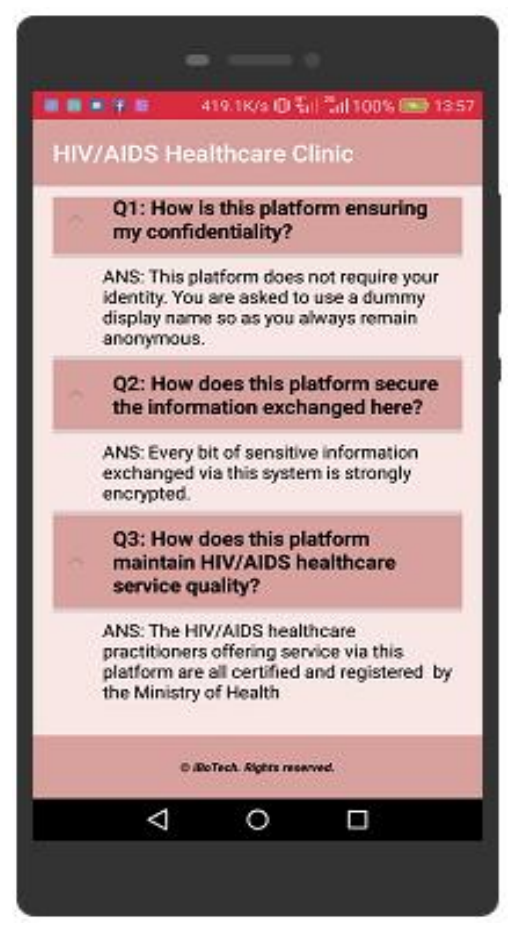

(b)

Figure 15: Mobile Application's FAQ UI 

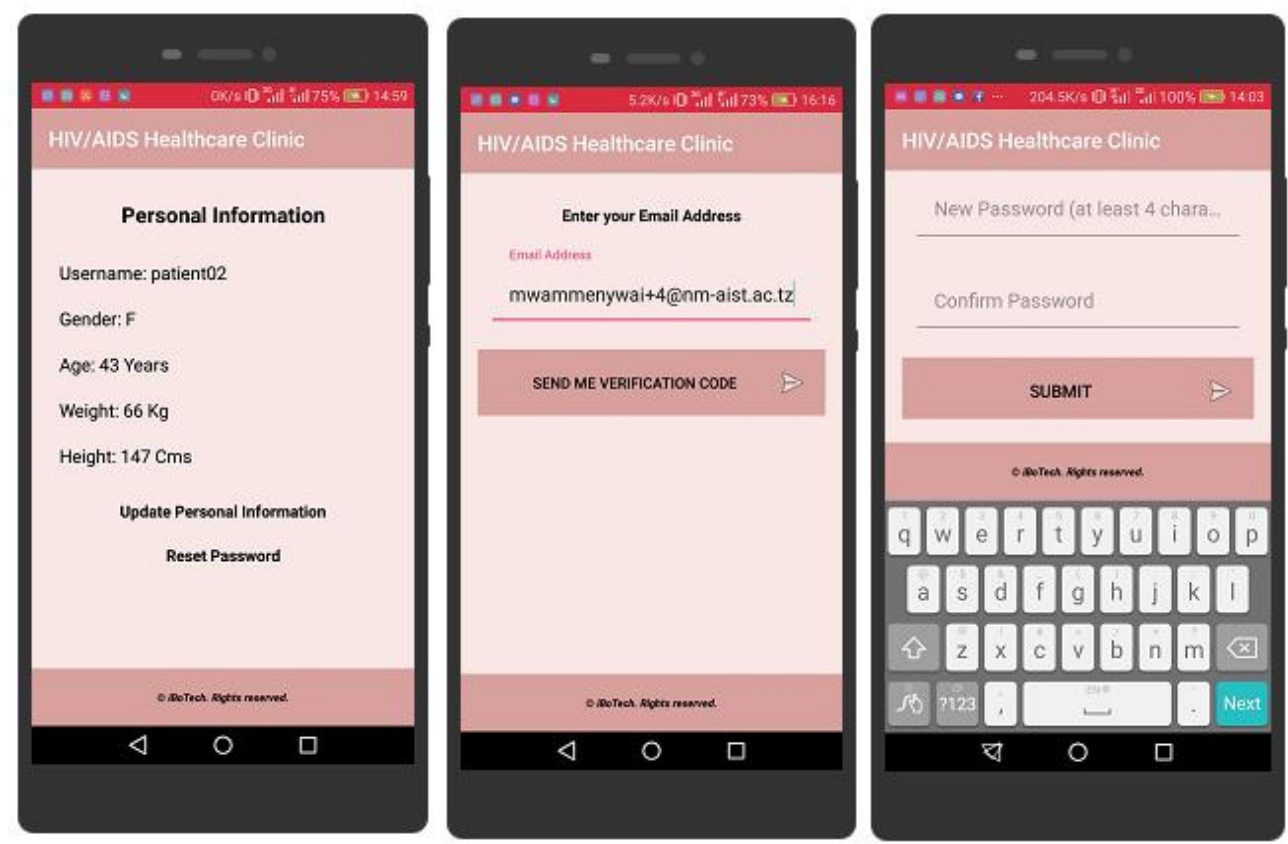

Figure 16: Mobile Application's Client Profile UI

Table 3: The System's User Acceptance Validation Response

\begin{tabular}{|c|c|c|c|c|c|c|}
\hline \multirow[b]{2}{*}{ Validation Aspect } & \multicolumn{5}{|c|}{ Number of Respondents } & \multirow{2}{*}{ 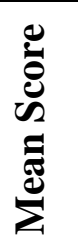 } \\
\hline & 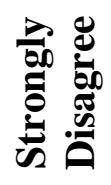 & 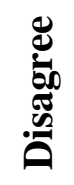 & $\begin{array}{l}\stackrel{0}{0} \stackrel{\Xi}{\Xi} \\
\ddot{Z}\end{array}$ & 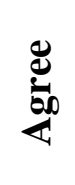 & 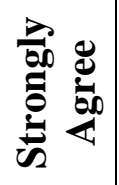 & \\
\hline $\begin{array}{l}\text { The system's interfaces are attractive and } \\
\text { interactive }\end{array}$ & 0 & 0 & 1 & 5 & 9 & 4.53 \\
\hline $\begin{array}{l}\text { The system's contents are easy to learn and } \\
\text { understand }\end{array}$ & 0 & 1 & 1 & 3 & 10 & 4.47 \\
\hline $\begin{array}{l}\text { No compatibility problems between the } \\
\text { system and your mobile phone and/or } \\
\text { computer's web-browser }\end{array}$ & 0 & 0 & 0 & 3 & 12 & 4.80 \\
\hline $\begin{array}{l}\text { I need further training and/or technical } \\
\text { assistance for fully exploit this system }\end{array}$ & 8 & 4 & 2 & 1 & 0 & 1.73 \\
\hline $\begin{array}{l}\text { The system is useful and helpful in accessing } \\
\text { the HIV/AIDS healthcare services }\end{array}$ & 0 & 0 & 3 & 7 & 5 & 4.13 \\
\hline $\begin{array}{l}\text { The system provides an easy and confidential } \\
\text { interactive between a client and HIV/AIDS } \\
\text { healthcare practitioner }\end{array}$ & 0 & 0 & 3 & 5 & 7 & 4.27 \\
\hline $\begin{array}{l}\text { I will use this system for accessing or } \\
\text { delivering HIV/AIDS healthcare information }\end{array}$ & 0 & 0 & 0 & 4 & 11 & 4.73 \\
\hline I am generally satisfied with this system & 0 & 0 & 1 & 4 & 10 & 4.60 \\
\hline I will recommend others to use this system & 0 & 0 & 0 & 5 & 10 & 4.67 \\
\hline
\end{tabular}




\section{CONCLUSIONS AND RECOMMENDATIONS}

With this developed integrated e-health platform, an easy, timely and secured access to relevant HIV/AIDS healthcare information can be achieved. This is due to the fact that clients must not have to physically and frequently visit the HIV/AIDS CTCs for accessing the HIV/AIDS healthcare information which can also be accessible through this developed electronic platform. This is so essential in enabling people to access HIV/AIDS healthcare counselling and recommendations without being disclosed, identified and subjected to the stigma and hence, saving their lives.

The developed e-health platform provides people with the electronic profile and the consultation history for future references. This electronic consultation reference can be frequently reviewed by the particular client without frequently visiting the HIV/AIDS CTCs for similar cases. It hence provides a client with his/her specific HIV/AIDS healthcare recommendations as close as to his/her mobile phone. Furthermore, the proper usage of the developed platform can significantly save the financial and time cost to clients. The clients will normally not have to spend the money to travel to the HIV/AIDS CTCs and/or spend their time in waiting queues at the CTCs because they can easily interact with the HIV/AIDS healthcare practitioners using a secure mobile application in their phones.

Moreover, the developed platform will provide all other HIV/AIDS stakeholders such as the government, policy makers, HIV/AIDS related Non-Government Organizations (NGOs) and researcher with the instant HIV/AIDS statistical data. Using this computerized system, the realtime statistical data can be achieved, provided to the correct approved person for proper usage, and also be useful to the government in policy development related to the HIV/AIDS matters.

The improvements should focus on making this platform to be interoperable to other existing e-health platforms. Furthermore, the study can be expanded to also work on the USSD platform in order to help people who do not have smartphones and/or have access to internet.

\section{ACKNOWLEDGMENTS}

We would like to thank God almighty for giving us this wonderful opportunity to undertake this research study by providing us with the right people and resources at the right time. We would like to extend our acknowledgments to the German Academic Exchange Service (DAAD) for funding the preparation of this manuscript and the University of Dar es Salaam for granting an academic leave to the corresponding author.

\section{REFERENCES}

Argyridis A. and Argialas D.P. (2015). A fuzzy spatial reasoner for multi-scale GEOBIA ontologies Photogrammetric Engineering and Remote Sensing, 81(6): 491-498. DOI: $10.14358 /$ PERS.81.6.491

Bor J., Herbst A.J., Newell, M.L. and Barnighausen T. (2013). Increases in adult life expectancy in rural South Africa: Valuing the scale-up of HIV treatment. Science, 339(6122): 961965. doi: 10.1126/science.1230413.

Bray T. (2017). The javascript object notation (json) data interchange format (No. RFC 8259)

Cole-Lewis H. and Kershaw T. (2010). Text messaging as a tool for behaviour change in disease prevention and management. Epidemiol Rev, 32(1): 56-69. doi: 10.1093/epirev/mxq004 
Crockford D. (2006). The application/json media type for JavaScript object notation (json) (No. RFC 4627).

Daassnet. (2018). Available online at http://www.daassnet.com/new/index.ph $\mathrm{p} / \mathrm{en} /$ professionalservices/d-d.html

Retrieved on 24th August 2018.

Dawson M., Burrell D.N., Rahim E. and Brewster S. (2010). Integrating software assurance into the software development lifecycle (SDLC). Journal of Information Systems Technology and Planning, 3(6): 49-53.

Fette I. and Melnikov A. (2011). The WebSocket protocol (No. RFC 6455)

Feyissa G.T., Abebe L., Girma E. and Woldie, M. (2012). Stigma and discrimination against people living with HIV by healthcare providers, Southwest Ethiopia. BMC Public Health, 12: 522. doi: 10.1186/14712458-12-522.

Hanafiah M. and Kasirun Z.M. (2007). Using Rule-Based Technique in Developing the Tool for Finding Suitable Software Methodology. Malaysian Journal of Computer Science, 20(2): 209-224. https://doi.org/10.22452/mjcs.vol20no2. 8

Hirschberg M.A. (2015). STN 2-1 Topic: Rapid Application Development (RAD): A Brief Overview. Available online https://www.mendeley.com/library/vie wer $/$ filleId $=6 f 1 \mathrm{c} 4 \mathrm{f} 30-\mathrm{d} 7 \mathrm{da}-50 \mathrm{~d} 9-67 \mathrm{a} 7-$ 2c02747d1f83 Retrieved on 24th August 2018

Ismail N.N.S. (2018). Implementing Rapid Application Development (RAD) methodology in developing Online Laboratory and Room Booking System (eLABAS). E Proceeding National Innovation and Invention Competition Through Exhibition (ICompEx'17).

Lwoga E.T., Nagu T. and Sife A.S. (2017). Online HIV Information Seeking Behaviour Among People Living with HIV in Selected Tanzanian Public Hospitals, Journal of Systems and
Information Technology, 19(1/2): 94115. DOI: 10.1108/JSIT-06-2016-0038

Mbonu N.C., van den Borne B. and De Vries N.K. (2009). Stigma of People with HIV/AIDS in Sub-Saharan Africa: A Literature Review. Journal of Tropical Medicine, 1-14. doi: 10.1155/2009/145891

Mechael P., Batavia H., Kaonga N., Searle S., Kwan A., Goldberger A. and Ossman J. (2010). Barriers and Gaps Affecting mHealth in Low and MiddleIncome Countries: Policy White Paper.

Mwammenywa I. A. and Kaijage S.F. (2018a). Towards Enhancing Access of HIV/AIDS Healthcare Information in Tanzania: Is a Mobile Application Platform a Way Forward? International Journal of Information Technology and Computer Science (IJITCS), 10(7): 3138. DOI: 10.5815/ijitcs.2018.07.04

Mwammenywa I.A. and Kaijage S.F. (2018b). HIV/AIDS Healthcare Information Delivery in Tanzania using Integrated Mobile Application and Web-based System: System's Functional and Non-functional Requirements. International Journal of Information Technology and Computer Science (IJITCS), 10(11): 30-38. DOI: $10.5815 /$ ijitcs.2018.11.03

Naz R. and Khan M.N.A. (2015). Rapid applications development techniques: A critical review. International Journal of Software Engineering and Its Applications, 9(11): 163-176. http://dx.doi.org/10.14257/ijseia.2015.9 .11 .15

Pimentel V. and Nickerson B.G. (2012). Communicating and displaying realtime data with WebSocket. IEEE Internet Computing, 16(4): 45-53. DOI: 10.1109/MIC.2012.64

Porebski, B., Przystalski, K. and Nowak, L. (2011). Building PHP Applications with Symfony, CakePHP, and Zend Framework. John Wiley and Sons.

Qiang C.Z., Yamamichi M., Hausman V., Miller R. and Altman D. (2012). Mobile Applications for the Health Sector. 
Radescu R., Davidescu A. and Pupezescu V. (2011). New Database Manipulation Tools in the Easy-Learning On-Line Platform. Online Submission.

Ragunath P.K., Velmourougan S., Davachelvan P., Kayalvizhi S. and Ravimohan R. (2010). Evolving a new model (SDLC Model-2010) for Software Development Life Cycle (SDLC). International Journal of Computer Science and Network Security, 10(1): 112-119.

Reto M. (2009). Professional android application development. Word Programmer to Programmer, 6(7): 1794-1797.

Saki M., Kermanshahi S.M.K., Mohammadi E. and Mohraz M. (2015). Perception of Patients With HIV/AIDS from Stigma and Discrimination.
Iranian Red Crescent Medical Journal, 17(6): e23638. doi: $10.5812 /$ ircmj.23638v2

Statista (2019). Global Mobile OS Market Share in Sales to End Users from 1st quarter 2009 to 2nd quarter 2018. Available online at https://www.statista.com/statistics/2661 36/global-market-share-held-bysmartphone-operating-systems/. Retrieved on 17th July 2019

The Joint United Nations Programme on HIV/AIDS (2016). Global HIV statistics. Retrieved from www.unaids.org/sites/default/files/medi a_asset/global-AIDS-update2016_en.pdf

van Genuchten R., Haring W., van Kassel D. and Yakubi K. (2012). Mobile phone use in Tanzania. TAN2012 Mark. Res. 